\title{
ATRIBUTOS QUALITATIVOS E FATORES DE SATISFAÇÃO COM O TRANSPORTE PÚBLICO URBANO POR ÔNIBUS
}

\author{
QUALITATIVE ATTRIBUTES AND SATISFACTION FACTORS \\ WITH URBAN PUBLIC TRANSPORT BUS SERVICE
}

\section{ATRIBUTOS CUALITATIVOS Y FACTORES DE SATISFACCIÓN CON EL TRANSPORTE PÚBLICO URBANO CON ÓMNIBUS}

Elaine Görgen Strehl

Mestra em Administração - Universidade de Santa Cruz do Sul, Santa Cruz do Sul, Brasil Professora de Ciências Contábeis - Universidade do Vale do Taquari, Lajeado, Brasil

elaine_gs@terra.com.br

\section{Carlos Alberto Mello Moyano}

Doutor em Administração - Universidade Federal do Rio Grande do Sul, Porto Alegre, Brasil Professor Pesquisador do Departamento de Administração e do Programa de Pós-Graduação em Administração (PPGA) - Universidade de Santa Cruz do Sul, Santa Cruz do Sul, Brasil carlos@unisc.br

\section{Derli Luís Angnes}

Mestre em Administração - Universidade de Santa Cruz do Sul, Santa Cruz do Sul, Brasil derli.angnes@gmail.com

\author{
Contextus \\ ISSNe 2178-9258 \\ Organização: Comitê Científico Interinstitucional \\ Editor-Chefe: Diego de Queiroz Machado \\ Avaliação: double blind review pelo SEER/OJS \\ Recebido em 30/08/2018 \\ Aceito em 06/11/2018 \\ $2^{\mathrm{a}}$ versão aceita em $13 / 11 / 2018$ \\ http://dx.doi.org/10.19094/contextus.v17i1.33530
}

\begin{abstract}
RESUMO
O crescimento das cidades tem influenciado a mobilidade urbana. Os meios de transporte coletivo representam uma maneira de amenizar os problemas de locomoção, sendo a satisfação dos usuários um dos principais indicadores da qualidade do serviço prestado. Objetivando identificar os atributos qualitativos e os fatores que impactam na satisfação com a qualidade de ônibus urbanos, realizou-se este estudo. Inicialmente, fez-se uma investigação exploratória e qualitativa com 25 usuários de ônibus, levantando os atributos qualitativos. Posteriormente, avaliou-se a satisfação com tais atributos, envolvendo uma amostra de 203 usuários. Resultou uma correlação significativa entre a satisfação geral dos usuários e a intenção de utilizar novamente o serviço de transporte público. Também se identificaram seis fatores preponderantes para a satisfação com o serviço de ônibus urbano: atendimento ao passageiro, informações ao passageiro, veículo de transporte, serviço de transporte público, estrutura das paradas de ônibus e ambiente das paradas.
\end{abstract}

Palavras-chave: serviços; transporte público; ônibus; qualidade; satisfação dos usuários.

\begin{abstract}
The growth of cities has influenced urban mobility. Means of collective transport represent a way to ease the problems of locomotion, and user satisfaction is one of the main indicators of the quality of the service provided. In order to identify the qualitative attributes and the factors that impact the satisfaction with urban bus quality, this study was carried out. Initially, an exploratory qualitative investigation was conducted with 25 bus users, raising the qualitative attributes. Subsequently, satisfaction with these attributes was evaluated, involving a sample of 203 users. There was a significant correlation between general user satisfaction and the intention to use the public transport service again. Six prevailing factors were also identified for satisfaction with the urban bus service: passenger support, information to the passenger, transportation vehicle, public transport service, structure of bus stops and stopover environment.
\end{abstract}


Keywords: services; public transportation; bus; quality; passenger satisfaction.

\section{RESUMEN}

El crecimiento de las ciudades ha influido en la movilidad urbana. Los medios de transporte colectivo representan una manera de amenizar los problemas de locomoción, siendo la satisfacción de los usuarios uno de los principales indicadores de la calidad del servicio prestado. Objetivando identificar los atributos cualitativos y los factores que impactan en la satisfacción con la calidad de los autobuses urbanos, se realizó este estudio. Inicialmente, se hizo una investigación exploratoria y cualitativa con 25 usuarios de autobuses, levantando los atributos cualitativos. Posteriormente, se evaluó la satisfacción con tales atributos, involucrando una muestra de 203 usuarios. Resultó una correlación significativa entre la satisfacción general de los usuarios y la intención de utilizar nuevamente el servicio de transporte público. También se identificaron seis factores preponderantes para la satisfacción con el servicio de autobús urbano: atención al pasajero, información al pasajero, vehículo de transporte, servicio de transporte público, estructura de las paradas de autobús y ambiente de las paradas.

Palabras clave: servicios; transporte público; autobús; calidad; satisfacción de los usuarios.

\section{INTRODUÇÃO}

Muitas das cidades brasileiras apresentam graves problemas com o transporte público e com a qualidade de vida, de acordo com pesquisas do Instituto de Pesquisa Econômica Aplicada - IPEA (2017). Os fatores incluem baixa mobilidade e acessibilidade, poluição ambiental urbana e alto índice de acidentes de trânsito, potencializando o caos urbano e exigindo das prefeituras maior planejamento do trânsito e do transporte público.

No que se refere às políticas urbanas de mobilidade, o Estatuto das Cidades, promulgado pela Lei $\mathrm{n}^{\mathrm{o}} 10.257$ de 10 de julho de 2001, e a Lei da Mobilidade Urbana, ou seja, a Lei $\mathrm{n}^{\circ}$ 12.587, de 3 de janeiro de 2012, instituíram instrumentos para concretizar o princípio da participação social na gestão democrática da cidade. Os arts. 14 e 15 da Lei no 12.587/2012, por exemplo, garantiram aos usuários do transporte coletivo o direito de participar do planejamento, da fiscalização e da avaliação da política local nos serviços, por meio de órgãos colegiados, ouvidorias, audiências e consultas públicas, além de outros procedimentos sistemáticos de comunicação, avaliação e prestação de contas (BRASIL, 2012).

Para uma construção social, econômica e de mobilidade urbana, os serviços públicos são essenciais. Sem o acesso a eles, as pessoas estarão seriamente limitadas para desenvolver suas capacidades, exercer seus direitos ou equiparar oportunidades. O transporte coletivo urbano no Brasil, previsto na Constituição Federal, artigo 30, inciso V, é considerado serviço público de caráter essencial, porque assim o definiu a sociedade, representada pelos constituintes. Ademais, não só o usuário direto, mas a sociedade como um todo se beneficia da existência e do funcionamento dos serviços (BRASIL, 1988). Posteriormente, a Emenda Constitucional $\mathrm{n}^{\circ} 90$, de 15 de setembro de 2015, introduziu o transporte como direito social (BRASIL, 2015). 
O ônibus é o veículo mais utilizado para o transporte coletivo de passageiros no país (IPEA, 2017; MURÇA; MÜLLER, 2014), ressaltando dessa forma a participação do ônibus no transporte de passageiros como de suma importância para a locomoção e a mobilidade em cidades brasileiras, além de outros meios (trens, metrôs, táxis etc.). Ademais, as concentrações urbanas modernas têm no transporte de passageiros um dos problemas mais difíceis e caros a resolver, mas impossível de ser adiado, porque hoje o desenvolvimento de um país depende, em grande parte, do modo de transporte das pessoas (DÍAZ; BERNABÉ, 2015).

No estudo de Lima, Moura e Souki (2015), o Brasil contava em 2015 com 20 bilhões de passageiros de ônibus. Desde a década de 1970, há estudos relacionados à satisfação dos serviços prestados, porém os modelos de pesquisa valorizam mais o desempenho operacional dos sistemas - como velocidade, custo, número de acidentes - do que propriamente os atributos e fatores salientes aos usuários, como conveniência, conforto etc. Murça e Müller (2014) também destacam a importância de estudos e pesquisas acerca da demanda de ônibus no Brasil dada a relevância que esse meio de transporte representa na mobilidade urbana dos brasileiros. As pesquisas sobre os atributos e fatores relacionados com a satisfação no transporte público por ônibus ainda são incipientes e devem ser ampliados no país para monitorar e aprimorar os tais serviços (BARCELOS et al., 2017a; 2017b);

Diante do exposto, evidencia-se a necessidade de estudos para identificar os atributos e seus fatores que promovem a satisfação dos usuários com a qualidade dos serviços de transporte público urbano de ônibus. $\mathrm{O}$ atendimento satisfatório à demanda social nos centros urbanos contribui não apenas para a mobilidade dos usuários, mas para a sua qualidade de vida. Uma vez identificados os atributos salientes ou declarados pelos usuários, os quais impactam na qualidade dos serviços de transporte coletivo, é possível medir a satisfação e insatisfação com o serviço, bem como identificar os fatores de maior relevância na qualidade do transporte, o que permitirá estabelecer políticas, cláusulas na licitação de concessões municipais e ações de fiscalização do Poder Público junto aos prestadores de serviços de transporte coletivo. A investigação também possibilita um benchmarking com foco na satisfação dos usuários de ônibus visando à melhoria contínua do transporte público (BARCELOS et al., 2017a). Quanto mais um serviço envolve os usuários e a população, mais importante se torna ampliar os níveis de satisfação. As empresas vivenciam um momento diferente, em que não basta ter uma estrutura definida e os melhores meios de execução, nem dispor de amplos recursos financeiros, se o prestador não souber identificar os atributos e fatores que satisfazem o seu público-alvo.

O presente estudo tem como principal objetivo identificar os atributos qualitativos e os 
fatores que impactam na satisfação com a qualidade dos serviços de transporte público urbano de ônibus, contribuindo dessa forma para ampliar os poucos estudos acadêmicos publicados no Brasil relacionados com a satisfação e a qualidade no transporte público urbano. A pesquisa foi realizada em duas etapas. Inicialmente, uma de natureza exploratória qualitativa identificou os atributos mais salientes e declarados pelos usuários de ônibus, o que subsidiou a formulação do instrumento de pesquisa descritiva posterior para medir a satisfação com os atributos, envolvendo apenas usuários de transporte coletivo de ônibus em uma cidade no Rio Grande do Sul. A partir dos resultados, foi possível extrair os principais fatores com impacto sobre a satisfação dos usuários com a qualidade do serviço de transporte.

Após este introito, sucede-se uma breve revisão bibliográfica acerca de transporte coletivo, acessibilidade e mobilidade urbana, bem como qualidade no transporte público e satisfação com ele. A seção 3 aborda a metodologia empregada, e a 4 apresenta a análise e discussão dos resultados da pesquisa em consonância com o objetivo proposto.

\section{REFERENCIAL TEÓRICO}

O referencial teórico é constituído de três tópicos: transporte coletivo, acessibilidade e mobilidade urbana; qualidade no transporte público; e satisfação com o transporte público.

\subsection{Transporte coletivo, acessibilidade e mobilidade urbana}

Conceitua-se transporte como o deslocamento de pessoas e de produtos. O deslocamento de pessoas é referido como transporte de passageiros e o de produtos, como transporte de carga. Enquanto um dicionário da língua portuguesa (MICHAELIS, 2017) denomina transporte como o ato ou efeito de transportar e urbano como relativo ou pertencente à cidade, o termo "transporte urbano" é empregado para designar os deslocamentos de pessoas e produtos realizados no interior das cidades. O transporte coletivo pode ser considerado como um meio de transporte utilizado por muitas pessoas simultaneamente, tornando o custo unitário baixo e de acesso público, sendo o serviço prestado por uma empresa ou prefeitura. Não existe flexibilidade de uso, pois os itinerários e os horários são fixos, e as viagens não são de porta a porta, havendo necessidade de completá-las com percursos a pé ou utilizando outros modos. Uma das formas mais comuns de transporte coletivo é o de ônibus. 
A Lei ${ }^{\circ}$ 12.587, de 3 de janeiro de 2012 institui diretrizes da Política Nacional de Mobilidade Urbana, citando em seu Art. $3^{\circ}$ “[...] o conjunto organizado e coordenado dos modos de transporte, de serviços e de infraestruturas que garantem o deslocamento de pessoas e cargas no território do Município". Neste aspecto, são classificadas as modalidades de transporte urbano, sendo motorizado e não motorizado; quanto ao serviço pode ser classificado conforme seu objetivo: transportar passageiros e/ou cargas; também, quanto à característica do serviço: coletivo ou individual; bem como a sua natureza: público ou privado. Por fim, o $\S 3^{\circ}$ da lei mencionada dispõe sobre as infraestruturas de mobilidade urbana, como: vias, demais logradouros públicos, estacionamentos; terminais, estações, conexões; locais para embarque e desembarque de passageiros, cargas; sinalização de trânsito; equipamentos e instalações; instrumentos de controle, fiscalização, arrecadação de taxas, tarifas e difusão de informações (BRASIL, 2012).

Nota-se que a relação jurídica entre a empresa de ônibus e o passageiro é uma relação de consumo. Isto posto, o transporte coletivo ofertado pelas empresas de ônibus no território nacional é muitas vezes fornecido de forma inadequada, ineficiente e não possui condições necessárias a garantir a segurança do passageiro. Verifica-se, no cotidiano das grandes cidades brasileiras, um número insuficiente de ônibus para atender aos anseios da população e uma frota elevada de veículos particulares. Por conseguinte, recai sobre a população o ônus de aguardar de forma demasiada na fila do embarque, bem como ingressar em ônibus superlotados, dificultando a acessibilidade ao serviço.

A acessibilidade, apesar de discutida desde o século XIX, foi retomada recentemente como assunto de suma importância para um planejamento urbano, por ser um instrumento capaz de identificar áreas com desigualdades na oferta de infraestrutura básica e por estar diretamente relacionado à qualidade de vida dos cidadãos. Para Cocco e Miralles-Guasch (2016), a acessibilidade econômica ao transporte é um tópico fundamental, na medida em que $38 \%$ dos deslocamentos nas metrópoles brasileiras são efetuados a pé em longas distâncias (por um segmento social sem outra opção). Desse modo, a acessibilidade acaba por influenciar a qualidade de vida das pessoas.

Acessibilidade consiste na possibilidade de todas as pessoas - sejam elas crianças, gestantes, pessoas com mobilidade reduzida ou pessoas com deficiência - terem condições de utilizar, com autonomia e segurança, os equipamentos e mobiliário urbanos, as edificações, os meios de transporte, as tecnologias e sistemas de informação disponíveis, bem como os serviços públicos ou abertos ao público. A acessibilidade ao sistema de transporte coletivo está 
relacionada com as distâncias que os usuários caminham quando utilizam o transporte coletivo, desde a origem da viagem do ponto de embarque até o ponto de desembarque no destino final. Quanto menos o passageiro caminhar, melhor é a acessibilidade ao sistema de transporte público. A acessibilidade do sistema de transportes considera a facilidade de acesso aos diferentes locais da área analisada (ARAÚJO; MAIA, 2016).

Os estudos de acessibilidade são variados e possuem diferentes direções, de acordo com os objetivos possíveis em cada situação. No entanto, todos eles visam quantificar ou medir as facilidades e/ou dificuldades de acesso. Desta forma, o conceito de acessibilidade relacionado ao modo de transporte em estudo pode ser dividido, para melhor compreensão e análise futura dos dados, em dois conceitos complementares: Acessibilidade ao Sistema de Transporte, que mediria a facilidade do usuário acessar o sistema de transporte coletivo em sua região de moradia, trabalho etc., e Acessibilidade a Destinos, que mediria após o acesso ao sistema de transporte, a facilidade de se chegar ao local desejado. Assim sendo, a acessibilidade ao sistema de transporte está diretamente relacionada às características da rede: sua configuração, localização, distância entre pontos de parada etc.

A precariedade do serviço de transporte coletivo urbano é um problema frequente no cotidiano dos brasileiros, razão pela qual foi editada a Lei 12.587/2012, tendo como um dos seus objetivos proporcionar a melhoria nas condições urbanas da população no que se refere à acessibilidade e à mobilidade. Em reforço, a lei em comento ainda prevê os direitos dos usuários do transporte coletivo, a saber (BRASIL, 2012):

Art. 14. São direitos dos usuários do Sistema Nacional de Mobilidade Urbana, sem prejuízo dos previstos nas Leis nos 8.078, de 11 de setembro de 1990, e 8.987, de 13 de fevereiro de 1995.

I - receber o serviço adequado, nos termos do art. $6^{\circ}$ da Lei no 8.987, de 13 de fevereiro de 1995;

II - participar do planejamento, da fiscalização e da avaliação da política local de mobilidade urbana;

III - ser informado nos pontos de embarque e desembarque de passageiros, de forma gratuita e acessível, sobre itinerários, horários, tarifas dos serviços e modos de interação com outros modais; e

IV - ter ambiente seguro e acessível para a utilização do Sistema Nacional de Mobilidade Urbana, conforme as Leis $\mathrm{n}^{\text {os }} 10.048$, de 8 de novembro de 2000, e 10.098, de 19 de dezembro de 2000.

Parágrafo único. Os usuários dos serviços terão o direito de ser informados, em linguagem acessível e de fácil compreensão, sobre:

I - seus direitos e responsabilidades;

II - os direitos e obrigações dos operadores dos serviços; e

III - os padrões preestabelecidos de qualidade e quantidade dos serviços ofertados, bem como os meios para reclamações e respectivos prazos de resposta.

Art. 15. A participação da sociedade civil no planejamento, fiscalização e avaliação da Política Nacional de Mobilidade Urbana deverá ser assegurada pelos seguintes instrumentos:

I - órgãos colegiados com a participação de representantes do Poder Executivo, da sociedade civil e dos operadores dos serviços;

II - ouvidorias nas instituições responsáveis pela gestão do Sistema Nacional de Mobilidade Urbana ou nos órgãos com atribuições análogas;

III - audiências e consultas públicas; e

IV - procedimentos sistemáticos de comunicação, de avaliação da satisfação dos cidadãos e dos usuários e de prestação de contas públicas. 
Todavia, a Política Nacional de Mobilidade Urbana não se resume a uma atuação dentro da própria cidade, limitada ao esforço pela melhoria do trânsito e transporte, mas sim a um conjunto de medidas e diretrizes voltadas ao desenvolvimento da mobilidade de toda a região abrangida e influenciada pelo município.

\subsection{Qualidade no transporte público}

Os serviços de transporte coletivo são mais expressivos em países ocidentais, oferecidos por empresas privadas ou semipúblicas, que operam de forma quase monopolista. Desta forma, muitas vezes, não estão focadas nas necessidades dos clientes (MOUWEN, 2015). A qualidade do transporte coletivo urbano pode ser mensurada pelos seus usuários através de alguns fatores. Estes são, segundo Ferraz e Torres (2004): a acessibilidade, tempo de viagem, lotação, confiabilidade, segurança e características dos locais de parada.

Para Rodrigues (2006), o serviço de transporte de pessoas é considerado uma atividade intermediária, cuja qualidade se baseia em rapidez, segurança e conforto. A qualidade em transporte minimiza gastos de energia e tempo dos usuários. $\mathrm{O}$ autor relaciona alguns fatores que influenciam a qualidade do transporte coletivo, como acessibilidade, frequência de atendimento, tempo de viagem, confiabilidade, segurança e características dos locais de parada.

Tais fatores podem variar em função do porte de cada cidade. De acordo com Lubeck et al. (2011), a relação de qualidade em serviços de transporte absorve características específicas resultantes de aspectos próprios do setor, que deve se adequar aos fatores centrais do gerenciamento do serviço, bem como às expectativas da sociedade. Barcelos et al. (2017a) destacam a necessidade de considerar os vieses socioculturais em pesquisas de satisfação dos usuários do transporte coletivo de ônibus, sobretudo se o foco for o benckmarking para a melhoria dos sistemas de transportes entre cidades brasileiras.

Todavia, as perspectivas dos usuários de transporte coletivo são importantes para determinar as melhores medidas políticas no referido transporte. A decisão pela escolha se motiva pela percepção da qualidade do serviço prestado. Em pesquisas feitas em cidades dos Estados Unidos da América, os usuários apontaram como fator de maior satisfação o acesso ao serviço frequente, confiável em um ambiente de segurança pessoal. Já na Tailândia, os resultados da mesma pesquisa apontaram como necessidades melhorar a acessibilidade nas 
paradas e garantir a segurança. Em Portugal, a satisfação dos usuários foi influenciada positivamente pelas sinalizações e negativamente pelo lixo existente (HERNANDEZ; MONZON; DE OÑA, 2016).

Nos estudos de Thompson e Schofield (2007), sobre a qualidade e desempenho do serviço de transporte público urbano na perspectiva de passageiros, os resultados se concentram sobre as atitudes dos usuários em matéria de adequação da oferta de transporte público existente. Já para Guirao, García-Pastor e López-Lambas (2016), o nível de qualidade desejado pelos passageiros e cidadãos em geral pode diferir da qualidade percebida. Segundo os autores, o nível de qualidade que a prestadora de serviços deve atingir é determinado por fatores externos e pressões, qualidade de espera, limitações orçamentárias e desempenho dos operadores.

A literatura descreve uma ligação entre qualidade no serviço e aumento da utilização de transporte coletivo, obrigando os responsáveis pelo serviço cada vez mais a investir em melhorias para orientar os usuários na escolha do melhor transporte ofertado. A avaliação de desempenho da qualidade no transporte coletivo é essencial para maximizar o impacto de melhorias. Desta forma, a qualidade do serviço prestado pelo operador influencia diretamente a experiência diária dos usuários. Identificar a percepção dos usuários é fundamental para definir um transporte eficiente e satisfatório (EPSTEIN; GIVONI, 2016).

Também se deve avaliar a qualidade do transporte coletivo urbano como um todo, de acordo com seus agentes no sistema: governo, usuários, trabalhadores, empresários e comunidade. Os usuários se valem do direito de utilizar um transporte público de baixo custo e de qualidade, assim o passageiro precisa ser reconhecido como um cliente, cujas necessidades devem ser sanadas (FERRAZ; TORRES, 2004). O uso do transporte coletivo também está relacionado com a qualidade de vida das pessoas (JAŚKIEWICZ; BESTA, 2014).

Promover a imagem de um serviço - um produto intangível - é um dos motivos para investir em sua qualidade. A imagem de um produto tangível influencia mais que a de um intangível as expectativas dos consumidores, pelo fato de a tangibilidade colaborar para a fase final, ou seja, para o momento em que o consumidor estiver diante do produto e confirmar uma expectativa anterior. Diferentemente ocorre no serviço, por oferecer uma avaliação do aspecto de tangibilidade (RODRIGUES, 2006). A imagem do serviço de transporte coletivo pode ser definida como o conjunto de ideias e impressões, racionais ou emocionais, que as partes racionais formam sobre a organização, neste caso sobre o prestador de serviços (HENSHER; 
HO; MULLEY, 2015). A imagem funciona como uma seleção da percepção dos consumidores em relação a qualidade, valor e satisfação, facilitando o processo decisório deles. A imagem é um efeito cumulativo da satisfação ou insatisfação do consumidor (ANDREASSEN; LINDESTAD, 1998).

As imagens resultam de todas as experiências, impressões e sentimentos do indivíduo quando em contato com um objeto ou quando submetido a determinada condição. Elas contribuem para formar as opiniões e sintetizam as decisões das pessoas e suas reações aos estímulos externos. Tais reações na solução de problemas definem o conceito de comportamento. Ressalta-se a importância da interpretação conjunta das variáveis imagens, comportamentos e opiniões, haja vista a sua essencialidade para a modelagem de questões sociais presentes (PAIVA JUNIOR, 2006). A imagem do transporte público é afetada pela qualidade dos serviços prestados aos usuários e influencia a decisão por sua utilização nas cidades.

A concorrência para o mercado é uma forma de aumentar a eficiência da qualidade na prestação de serviços do transporte (FILIPPINI; KOLLER; MASIERO, 2015). Muito é investido em novas infraestruturas de transporte para que os cidadãos tenham maior qualidade na prestação dos serviços e assim optem por esse meio de transporte, contribuindo dessa forma para o desenvolvimento sustentável (HENSHER; HO; MULLEY, 2015) e para a satisfação com o transporte público.

\subsection{Satisfação com o transporte público}

A satisfação do cliente pode ser compreendida como a avaliação da refutação entre a expectativa do cliente e o desempenho do serviço por ele percebido. O cliente considera-se satisfeito se o desempenho por ele experimentado atende ou excede a expectativa. Quando tem suas necessidades atendidas, possui uma tendência de retorno ao serviço (SHAN et al., 2014). A satisfação do cliente é uma resposta afetiva para uma diferença percebida entre expectativas e percepções. Um construto afetivo completo após uma experiência de prestação de serviços (MOUWEN, 2015). Para Abenoza, Cats e Susilo (2017), a satisfação do cliente é definida como a medida em que a prestação de serviços atende às necessidades dos clientes. As organizações que prestam serviços e comercializam intangíveis precisam buscar maneiras de diferenciar-se das demais organizações visando atrair a satisfação de seus clientes. O cliente de serviços deve 
ser visto como expressando opiniões e formando conceitos, que afetam, por sua vez, a imagem das organizações (BERRY, 2016).

Para Lima, Moura e Souki (2015), o Brasil contava em 2015 com 20 bilhões de passageiros de ônibus. Desde a década de 1970, há estudos relacionados à satisfação dos serviços prestados no transporte, porém os modelos de pesquisa valorizam mais o desempenho operacional dos sistemas - como velocidade, custo e número de acidentes - do que propriamente os atributos, como conveniência, satisfação e conforto.

Pesquisou-se, pelo Portal de Periódicos da CAPES, as bases de dados Web Of Science (WOS) e SCOPUS com as palavras-chave: Quality on the public transport AND Satisfaction of public transport users. No caso da WOS, recuperaram-se 51 trabalhos entre os anos de $2014 \mathrm{e}$ 2017, todos publicados no idioma inglês. Em seguida, adotou-se um processo de seleção de 10 artigos por ordem de publicação de mais recente a mais antiga que tratavam de pesquisas aplicadas a satisfação e qualidade no uso de ônibus. O Quadro 1 apresenta uma síntese dos resultados obtidos a partir da base de dados WOS.

Quadro 1 - Pesquisas sobre satisfação e qualidade com o transporte público (WOS)

\begin{tabular}{|c|c|c|c|}
\hline Autor (es) & Ano & Objetivo do Estudo & Amostra/Local \\
\hline $\begin{array}{l}\text { Grisé e El- } \\
\text { Geneidy }\end{array}$ & 2017 & $\begin{array}{l}\text { Avaliou os dados de levantamento da satisfação } \\
\text { com o serviço de ônibus em bairros de diferentes } \\
\text { níveis sociais da cidade de Londres, na Inglaterra. }\end{array}$ & $\begin{array}{l}\text { Pessoas entre } 20 \text { e } 64 \text { anos, após } \\
\text { viagem a trabalho ou estudos, } \\
\text { numa amostra de } 17.516 \\
\text { respondentes entre os anos de } \\
2010 \text { e } 2015 \text {, em } 198 \text { rotas. }\end{array}$ \\
\hline $\begin{array}{l}\text { Abenoza, Cats e } \\
\text { Susilo }\end{array}$ & 2017 & $\begin{array}{l}\text { A pesquisa identificou e caracterizou utilizadores de } \\
\text { transportes públicos na Suécia, além de mensurar a } \\
\text { satisfação com os serviços de transporte público } \\
\text { para cada segmento de viajantes. Também } \\
\text { investigou as mudanças, ao longo do tempo, na } \\
\text { importância de atributos entre os diferentes } \\
\text { segmentos e regiões geográficas em relação à } \\
\text { satisfação global. }\end{array}$ & $\begin{array}{l}\text { Amostra com } 453.564 \\
\text { entrevistados entre os anos de } \\
2001 \text { e } 2014 \text { em } 21 \text { cidades } \\
\text { suecas. }\end{array}$ \\
\hline $\begin{array}{l}\text { Efthymiou e } \\
\text { Antoniou }\end{array}$ & 2017 & $\begin{array}{l}\text { Investigou o impacto da crise na Grécia nos usuários } \\
\text { de transportes públicos, analisando sua satisfação e } \\
\text { a demanda pelo serviço. }\end{array}$ & $\begin{array}{l}\text { Foram realizadas } 600 \\
\text { entrevistas, sendo destas } 187 \\
\text { com usuários de ônibus, os } \\
\text { demais de metrô, trem e outros, } \\
\text { na cidade de Atenas. }\end{array}$ \\
\hline $\begin{array}{l}\text { Epstein e } \\
\text { Givoni }\end{array}$ & 2016 & $\begin{array}{l}\text { Avaliou a eficácia do transporte público de ônibus, } \\
\text { objetivando a melhoria da atratividade desse } \\
\text { serviço, a fim de promover a mobilidade sustentável } \\
\text { em Israel. }\end{array}$ & $\begin{array}{l}\text { Amostra com } 615 \text { participantes } \\
\text { em } 56 \text { paradas de ônibus. Os } \\
\text { entrevistados } \\
\text { interrogados sobre as suas } \\
\text { perspectivas e opinião dos } \\
\text { serviços de ônibus. }\end{array}$ \\
\hline Rahman et al. & 2016 & $\begin{array}{l}\text { Desenvolveu modelos empíricos para avaliar a } \\
\text { qualidade do transporte com base na experiência dos } \\
\text { usuários, em sua expectativa, em seu nível de } \\
\text { satisfação e em sua opinião sobre o serviço } \\
\text { existente. }\end{array}$ & $\begin{array}{l}\text { Amostra de } 2008 \text { usuários de } \\
\text { junho e julho de } 2015 \text { na cidade } \\
\text { de Dhaka em Bangladesh. }\end{array}$ \\
\hline
\end{tabular}

(CONTINUA) 


\section{(CONTINUAÇÃO)}

\begin{tabular}{|c|c|c|c|}
\hline Shaaban e Kim & 2016 & $\begin{array}{l}\text { Determinou a relação entre a satisfação do serviço } \\
\text { de ônibus e o transporte com estudantes } \\
\text { universitários no Catar. }\end{array}$ & $\begin{array}{l}\text { Amostra de } 330 \text { respondentes, } \\
\text { sendo estudantes da Qatar } \\
\text { University, no período de abril } \\
\text { de } 2014 \text {. }\end{array}$ \\
\hline Islam et al. & 2016 & $\begin{array}{l}\text { Comparou as capacidades de três abordagens } \\
\text { eficazes da Rede Neural Artificial. Para calibrar os } \\
\text { parâmetros, desenvolveu modelos ANN, } \\
\text { considerando dados sobre a percepção dos usuários } \\
\text { em relação aos serviços de ônibus de Dhaka em } \\
\text { Bangladesh. }\end{array}$ & $\begin{array}{l}\text { Uma amostra de } 655 \text { usuários, } \\
\text { sendo } 70 \% \text { dos entrevistados do } \\
\text { sexo masculino e } 30 \% \text { do } \\
\text { feminino. }\end{array}$ \\
\hline $\begin{array}{l}\text { De Oña, De } \\
\text { Oña e López }\end{array}$ & 2016 & $\begin{array}{l}\text { Estratificou usuários de transporte público na cidade } \\
\text { de Granada na Espanha, analisando a qualidade do } \\
\text { serviço, levando em conta os perfis detalhados dos } \\
\text { passageiros. A qualidade do serviço foi analisada } \\
\text { com e sem segmentação de perfis de passageiros de } \\
\text { modo que os resultados foram comparados entre si. }\end{array}$ & $\begin{array}{l}\text { Foram } 3.664 \text { entrevistados, } \\
\text { entre os anos de } 2008 \text { e } 2011, \\
\text { na área metropolitana. }\end{array}$ \\
\hline $\begin{array}{l}\text { Guirao, García- } \\
\text { Pastor e López- } \\
\text { Lambas }\end{array}$ & 2016 & $\begin{array}{l}\text { Propôs um método para estimar a importância } \\
\text { declarada do atributo qualidade em relação à } \\
\text { importância derivada, a partir da pesquisa de } \\
\text { preferência, considerando que o atributo é um } \\
\text { indicador de percepção do usuário. }\end{array}$ & $\begin{array}{l}\text { Foram } 293 \text { respondentes para } \\
\text { importância declarada e } 520 \\
\text { para importância derivada em } 4 \\
\text { linhas de ônibus urbanos em } \\
\text { Madri, na Espanha. }\end{array}$ \\
\hline $\begin{array}{l}\text { Charbatzadeh et } \\
\text { al. }\end{array}$ & 2016 & $\begin{array}{l}\text { Examinou o serviço de ônibus em duas } \\
\text { universidades de Taiwan, considerando a qualidade } \\
\text { não só com referência ao respeito e cuidados } \\
\text { prestados, mas também aos níveis de conforto no } \\
\text { ônibus. }\end{array}$ & $\begin{array}{l}\text { Foram } 847 \text { entrevistados, mais } \\
\text { precisamente duas } \\
\text { universidades que possuem o } \\
\text { serviço de ônibus aos seus } \\
\text { estudantes. }\end{array}$ \\
\hline
\end{tabular}

Fonte: elaboração própria.

Quanto à base de dados SCOPUS, a consulta com os mesmos termos retornou 263 artigos entre os anos de 1971 e 2018, a maioria publicados no idioma inglês (250). Em seguida, adotou-se um processo de seleção dos artigos com mais de 100 citações. O Quadro 2 apresenta uma síntese dos resultados obtidos.

Quadro 2 - Artigos mais citados em satisfação e qualidade no transporte público (Scopus)

\begin{tabular}{|l|l|l|l|c|}
\hline \multicolumn{1}{|c|}{ Autor (es) } & Ano & \multicolumn{1}{|c|}{$\begin{array}{c}\text { Objetivo do } \\
\text { Estudo }\end{array}$} & \multicolumn{1}{|c|}{ Amostra/Local } & $\begin{array}{c}\text { Citado } \\
\text { por }\end{array}$ \\
\hline $\begin{array}{l}\text { Hensher, } \\
\text { Stopher e } \\
\text { Bullock }\end{array}$ & 2003 & $\begin{array}{l}\text { Investiga maneiras de quantificar a } \\
\text { qualidade do serviço e compara os } \\
\text { níveis entre operadores de ônibus. }\end{array}$ & $\begin{array}{l}\text { Foram utilizadas 4.500 amostras de } \\
\text { passageiros em corredores de } \\
\text { ônibus na Austrália. }\end{array}$ & 206 \\
\hline Lai e Chen & 2011 & $\begin{array}{l}\text { Explora as relações entre as intenções } \\
\text { comportamentais do passageiro es os } \\
\text { vários fatores qualidade do serviço, } \\
\text { valor percebido satisfação) que afetam } \\
\text { a pesquisa teve 763 questionários } \\
\text { validados, aplicados com } \\
\text { passageiros do transporte público } \\
\text { de Kaohsiung, em Taiwan. }\end{array}$ & 203 \\
\hline $\begin{array}{l}\text { Tyrinopoulos e } \\
\text { Antoniou }\end{array}$ & 2008 & $\begin{array}{l}\text { Enfoca a percepção da satisfação do } \\
\text { passageiro sobre o desempenho do } \\
\text { trânsito, com ênfase na variabilidade da } \\
\text { qualidade entre os operadores de } \\
\text { transporte de passageiros. }\end{array}$ & $\begin{array}{l}\text { Foram examinados cinco sistemas } \\
\text { de trânsito em duas grandes } \\
\text { conurbações na Grécia, Atenas e } \\
\text { Salónica, totalizando uma amostra } \\
\text { de 1.474 passageiros pesquisados. }\end{array}$ & 174
\end{tabular}




\begin{tabular}{|c|c|c|c|c|}
\hline $\begin{array}{l}\text { Brons, Givoni } \\
\text { e Rietveld }\end{array}$ & 2009 & $\begin{array}{l}\text { Avalia a satisfação geral de passageiros } \\
\text { com o transporte de trem e investiga os } \\
\text { fatores que impactam a qualidade e o } \\
\text { aumento do transporte ferroviário de } \\
\text { passageiros. }\end{array}$ & $\begin{array}{l}\text { Utilizou-se amostra de } 17.033 \\
\text { passageiros na Holanda para avaliar } \\
\text { a satisfação com os serviços de } \\
\text { transporte por trem. }\end{array}$ & 144 \\
\hline $\begin{array}{l}\text { Givoni e } \\
\text { Rietveld }\end{array}$ & 2007 & $\begin{array}{l}\text { Analisa os meios modais utilizados por } \\
\text { pessoas para o acesso das estações } \\
\text { ferroviárias de transporte de } \\
\text { passageiros. }\end{array}$ & $\begin{array}{l}\text { Foi utilizada uma base de dados } \\
\text { contendo } 2.542 \text { casos na Holanda. }\end{array}$ & 116 \\
\hline Oña et al. & 2013 & $\begin{array}{l}\text { Propõe uma metodologia para avaliar a } \\
\text { qualidade do serviço percebida pelos } \\
\text { usuários de um serviço de transporte de } \\
\text { ônibus. }\end{array}$ & $\begin{array}{l}\text { Um total de } 1.200 \text { pesquisas foram } \\
\text { coletadas no transporte público de } \\
\text { ônibus em Granada (Espanha). }\end{array}$ & 100 \\
\hline
\end{tabular}

Fonte: elaboração própria.

Embora existam alguns trabalhos atuais no Brasil (BARCELOS et al., 2017a; 2017b), nenhum mais aprofundado atual foi identificado na base de dados WOS, e apenas seis artigos nacionais foram identificados na SCOPUS no período pesquisado (1971 a 2018), envolvendo o tema com cidades brasileiras, o que denota a importância de aprofundar o estudo acerca dos fatores de satisfação com transporte público por ônibus. Sobretudo pela predominância desse meio de transporte na maioria das cidades do país e, portanto, justamente por sua relevância social, o gerenciamento dos transportes coletivos depende da realização de estudos e análises de forma a atender satisfatoriamente a demanda (MURÇA; MÜLLER, 2014).

\section{METODOLOGIA}

O método empregado caracteriza-se basicamente por duas etapas de pesquisa. A primeira etapa, de natureza exploratória e análise qualitativa para uma maior compreensão sobre os atributos qualitativos salientes e declarados pelos usuários de transporte coletivo de ônibus, permitindo dessa forma identificar variáveis utilizadas no instrumento de pesquisa da segunda etapa, caracterizada como de natureza descritiva e análise quantitativa estatística, para aprofundar a compreensão dos fatores que exercem impacto sobre a satisfação com a qualidade dos serviços de transporte público de ônibus. Cada uma dessas etapas será detalhada na sequência.

Inicialmente, a primeira etapa foi concebida a partir de uma pesquisa exploratória qualitativa, para identificar os atributos que mais impactam a satisfação da qualidade dos usuários de serviço de transporte público do município de Estrela, na região central do Rio Grande do Sul. Dessa forma, o viés sociocultural é amenizado na mensuração a posteriori, pois não faz uso de escalas de fontes secundárias oriundas de outras populações. A pesquisa 
exploratória auxilia a compreender o problema de pesquisa e a obter dados adicionais, tendo como objetivo alcançar uma compreensão qualitativa das causas e incitações implícitas (MALHOTRA, 2011). Dentre as técnicas disponíveis para estudos exploratórios, optou-se pela técnica do incidente crítico (FLANAGAN, 1954). O levantamento dos incidentes críticos se dá por meio de relatos das experiências positivas e negativas vivenciadas pelos usuários de forma a incorporar o maior número possível sem descriminação, para uma posterior análise de conteúdo que inclua tanto os atributos positivos como os negativos. Neste estudo, adotou-se questionário não estruturado, aplicado a uma amostra por conveniência de 25 usuários de transporte coletivo de Estrela, para identificar os relatos dos usuários com incidentes positivos e negativos (incidentes críticos) com o serviço. Cada entrevistado descreveu até cinco experiências positivas e cinco negativas que vivenciou ao utilizar o serviço de transporte coletivo de ônibus no município. Após isso, os incidentes foram tabulados e analisados por dois especialistas, reunindo e classificando os incidentes de maior frequência, resultando nos atributos qualitativos categorizados em uma tabela.

A segunda etapa da pesquisa classifica-se como descritiva e quantitativa, que permite, segundo Cooper e Schindler (2016), a mensuração precisa de algo. O estudo descritivo é recomendado para situações em que se deseja responder questões específicas da pesquisa, cujo objetivo é descrever características e percepções de indivíduos, os quais aqui consistem nos usuários de transporte coletivo. Suas percepções giram em torno da qualidade do transporte público urbano por ônibus.

A percepção dos usuários pode ser utilizada na prática para fornecer subsídios para administração e o planejamento público na tomada de decisão. Cabe ao pesquisador identificar as variáveis mais importantes para o público e aplicar uma técnica sistemática para medi-las (ENDERS; MENDES; HESKETH, 1983), razão pela qual essas variáveis foram obtidas diretamente de fontes primárias na pesquisa exploratória da etapa inicial. Para tanto, foi utilizado um levantamento com os usuários do transporte coletivo, tendo como base os atributos de qualidade de maior relevância declarada pelos usuários. O procedimento de pesquisa descritiva adotado foi o levantamento ou survey, aplicado por meio de um questionário estruturado desenvolvido a partir dos atributos identificados na etapa inicial.

O questionário estruturado empregou uma escala de diferencial semântico de cinco pontos (1 - Muito Insatisfeito; 2 - Insatisfeito; 3 - Não Sei; 4 - Satisfeito e 5 Muito Satisfeito), cujos extremos da escala caracterizam os polos de insatisfação e satisfação, sendo o centro (3 Não Sei) considerado a região neutra da escala. De acordo com Malhotra (2011), a escala de 
classificação em pontos extremos está associada a rótulos bipolares, como por exemplo Insatisfação e Satisfação. A amostra caracteriza-se como não probabilística e por conveniência, envolvendo 203 usuários do serviço de transporte coletivo de ônibus urbano no município de Estrela (RS). Apenas passageiros com idade superior a 18 anos que utilizam o transporte coletivo urbano (ônibus) ao menos três vezes ao dia foram entrevistados, em diversos pontos da cidade, abrangendo o maior número de paradas de ônibus possíveis. O questionário utilizado possui alternativas de respostas fixas. Este tipo de questionário exige que o pesquisado faça a sua escolha em um conjunto predeterminado de respostas (MALHOTRA, 2011). O questionário teve como propósito medir a satisfação dos usuários de transporte coletivo a partir de variáveis (atributos) identificadas na etapa exploratória, para posteriormente analisar os fatores que compõem a satisfação com a qualidade dos serviços de transporte público urbano por ônibus em Estrela (RS).

Os dados foram analisados mediante estatística descritiva e multivariada com o emprego de técnicas de análise fatorial, por meio da utilização de recurso computacional dos softwares aplicativos Microsoft Excel® e SPSS® (Statistical Package for the Social Sciences). Os resultados foram descritos e apresentados em tabelas, quadros e gráficos, buscando respostas ao objetivo deste estudo e com a devida discussão dos resultados a partir do referencial teórico.

A Figura 1 mostra a sequência lógica da pesquisa, indo da identificação exploratória dos atributos qualitativos até a análise dos fatores de satisfação com o transporte público por ônibus.

Figura 1 - Sequência lógica da pesquisa

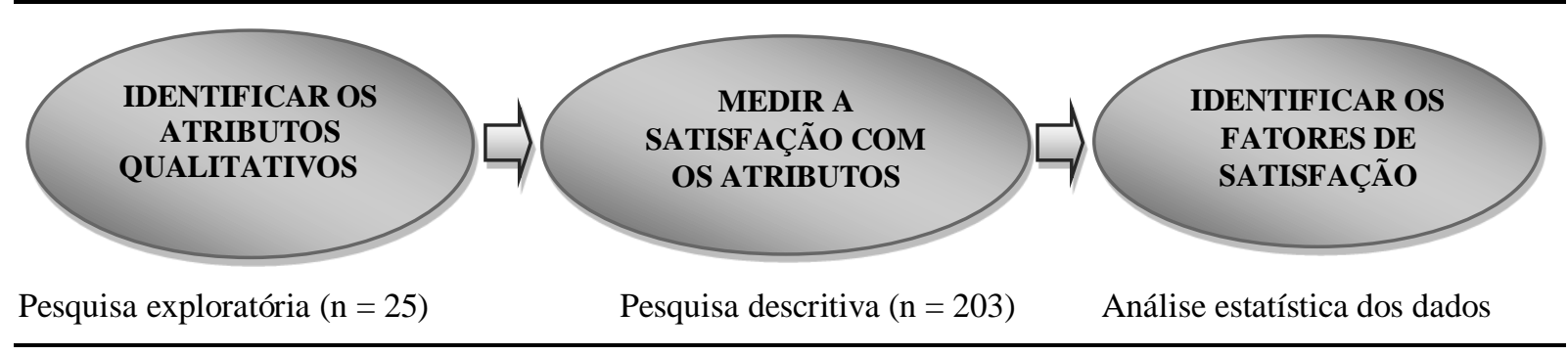

Fonte: elaboração própria.

\section{ANÁLISE E DISCUSSÃO DOS RESULTADOS}

Os resultados da pesquisa foram subdivididos em duas seções, a primeira abordando os resultados da etapa exploratória - os atributos qualitativos - e a segunda descrevendo os 
resultados da pesquisa de satisfação com os atributos juntamente com a análise dos fatores de satisfação da qualidade com o serviço de transporte público urbano por ônibus.

\subsection{Atributos qualitativos no transporte público de ônibus}

O perfil da amostra foi constituído por 25 usuários do serviço de transporte coletivo de ônibus na cidade de Estrela (RS), coletado dentro de um período de 15 dias, com passageiros com idade acima de 18 anos, que utilizaram o transporte coletivo ao menos três vezes por semana, tendo a pesquisa sido aplicada na primeira quinzena de junho de 2017.

Cada entrevistado tinha a opção de atribuir até cinco incidentes positivos e cinco negativos com base na sua experiência de viagem. Como resultado, 100 incidentes positivos e 122 incidentes negativos foram listados, totalizando 222 incidentes que, após analisados por especialistas e agrupados por semelhança e repetição de palavras, resultaram numa tabela contendo 20 atributos, categorizados em 6 dimensões teóricas (Tabela 1).

Tabela 1 - Atributos identificados com a técnica do incidente crítico

\begin{tabular}{|c|c|c|c|}
\hline Dimensão teórica & Atributos selecionados & Frequência & $\%$ \\
\hline $\begin{array}{l}\text { ATRIBUTOS DE } \\
\text { CONFORTO: }\end{array}$ & $\begin{array}{l}\text { - Estado de conservação dos veículos; } \\
\text { - Segurança para quem viaja de pé; } \\
\text { - Climatização do ônibus; } \\
\text { - Espaço do veículo; } \\
\text { - Espaço reservado para idosos e PNE (Portador de Necessidade } \\
\text { Especiais). }\end{array}$ & 75 & $34 \%$ \\
\hline $\begin{array}{l}\text { ATRIBUTOS DE } \\
\text { ITINERÁRIO: }\end{array}$ & $\begin{array}{l}\text { - Trajeto da viagem; } \\
\text { - Cumprimento dos trajetos; } \\
\text { - Número de veículos no mesmo horário; } \\
\text { - Cumprimento dos horários; } \\
\text { - Rapidez no trajeto. }\end{array}$ & 38 & $17 \%$ \\
\hline $\begin{array}{l}\text { ATRIBUTOS DE } \\
\text { PARADAS: }\end{array}$ & $\begin{array}{l}\text { - Limpeza das paradas; } \\
\text { - Segurança e iluminação das paradas; } \\
\text { - Cobertura das paradas; } \\
\text { - Bancos para sentar nas paradas. }\end{array}$ & 33 & $15 \%$ \\
\hline $\begin{array}{l}\text { ATRIBUTO DO } \\
\text { MOTORISTA: }\end{array}$ & $\begin{array}{l}\text { - Motorista cordial, simpático, atencioso...; } \\
\text { - Motorista educado. }\end{array}$ & 28 & $13 \%$ \\
\hline $\begin{array}{l}\text { ATRIBUTOS DE } \\
\text { INFORMAÇÃO: }\end{array}$ & $\begin{array}{l}\text { - Informação dos horários; } \\
\text { - Identificação dos veículos com itinerário; } \\
\text { - Informação do itinerário e horário nas paradas. }\end{array}$ & 27 & $12 \%$ \\
\hline $\begin{array}{l}\text { ATRIBUTO DE } \\
\text { PREÇO: }\end{array}$ & - Preço das passagens. & 21 & $9 \%$ \\
\hline TOTAL & & 222 & $100 \%$ \\
\hline
\end{tabular}

Fonte: elaboração própria.

Os incidentes/atributos representam fontes de informação para gerar indicadores de qualidade no serviço. Para Grisé e El-Geneidy (2017), os indicadores de desempenho nos serviços de ônibus são importantes para garantir que todos os clientes recebam a mesma 
qualidade de serviço prestado pelo operador. A dimensão teórica a reunir o maior número de atributos na pesquisa foi o conforto, com uma representatividade de $34 \%$ dos atributos mais citados, seguido de: itinerário, com 17\%; parada, com 15\%; motorista, com 13\%; informação, com 12\%; e preço, com 9\% das citações (Tabela 1). Essa relação de atributos corrobora e complementa outro estudo realizado por Barcelos et al. (2017b), acerca da importância dos atributos com o transporte coletivo de Porto Alegre (RS), com a seguinte ordem crescente dos atributos, baseada na importância declarada pelos usuários: $1^{\circ}$ Segurança pública, $2^{\circ}$ rapidez, $3^{\circ}$ disponibilidade, $4^{\circ}$ segurança contra acidentes de trânsito, $5^{\circ}$ conforto dos ônibus, $6^{\circ}$ acesso, $7^{\circ}$ gasto, $8^{\circ}$ confiabilidade, $9^{\circ}$ conforto dos pontos de ônibus, $10^{\circ}$ ruído e poluição, $11^{\circ}$ informação, $12^{\circ}$ atendimento, $13^{\circ}$ conforto dos terminais, $14^{\circ}$ pagamento e por fim, $15^{\circ}$ integração).

Também se destaca o estudo internacional de Hensher, Stopher e Bullock (2003), que identificou os atributos de maior impacto positivo sobre a satisfação dos passageiros de ônibus: assento para todos os passageiros, cumprimento do horário, cobertura e assento das paradas de ônibus, limpeza dos ônibus e motorista amigável. A descoberta desses atributos serve para vários propósitos e revela ao operador do serviço o que importa para os passageiros.

A partir dos resultados desta etapa exploratória qualitativa, foi possível elaborar um questionário estruturado contendo variáveis para medir a satisfação com a qualidade no serviço, com base nos atributos de percepção declarada dos usuários de ônibus de Estrela (RS). Isso possibilitou avançar para a etapa descritiva quantitativa, cujos resultados estão apresentados na seção subsequente.

\subsection{Fatores de satisfação dos usuários de ônibus}

A amostra foi composta por usuários de diversas linhas do transporte coletivo do município de Estrela (RS), com idade superior a 18 anos, a maioria $(68,5 \%)$ do sexo feminino. Foram aplicados e validados 203 questionários entre setembro e outubro de 2017. As medidas de satisfação envolveram 20 variáveis (atributos da Tabela 1) e mais duas questões: uma destinada a avaliar a satisfação global com o serviço de transporte coletivo e a outra, a medir a utilização do transporte novamente (fidelização). Os percentuais obtidos estão apresentados na Figura 2.

Os resultados obtidos foram satisfatórios. Segundo os entrevistados, 73,6\% consideramse satisfeitos em geral com o serviço de transporte público em Estrela (RS), e 90,5\% voltariam 


\section{ATRIBUTOS QUALITATIVOS E FATORES DE SATISFAÇÃO COM O TRANSPORTE PÚBLICO URBANO POR ÔNIBUS}

a utilizar o mesmo ônibus. Os atributos que obtiveram as melhores avaliações (acima de 70\% de satisfação) foram: Educação do motorista (88,3\% de satisfeitos); Cordialidade, simpatia e atenção do motorista ( $87 \%$ de satisfeitos); Trajeto (84,8\% de satisfeitos); Rapidez do trajeto (83,8\% de satisfeitos); Climatização do veículo (78,3\% de satisfeitos); Conservação do veículo (76,5\%); Cumprimento dos trajetos (76\%) e Limpeza das paradas $(75,1 \%)$.

Figura 2 - Percentuais de insatisfação e satisfação com a qualidade dos atributos

22. Utilização do transporte novamente 21. Satisfação global com o transporte coletivo

20. Preço das passagens

19. Informação do itinerário e horário nas paradas

18. Identificação do itinerário nos veículos

17. Disponibilidade dos horários em local visível

16. Educação do motorista

15. Cordialidade, simpatia e atenção do motorista

14. Bancos para sentar nas paradas

13. Cobertura das paradas 12. Segurança e iluminação das paradas

11. Limpeza das paradas 10. Rapidez no trajeto

9. Cumprimento dos horários

8. Número de veículos

7. Cumprimento dos trajetos

6. Trajeto

5. Espaço destinados a idosos e PNE

4. Espaço dos veículos

3. Climatização do veículo 2. Segurança para viajar de pé

1. Conservação do veículo

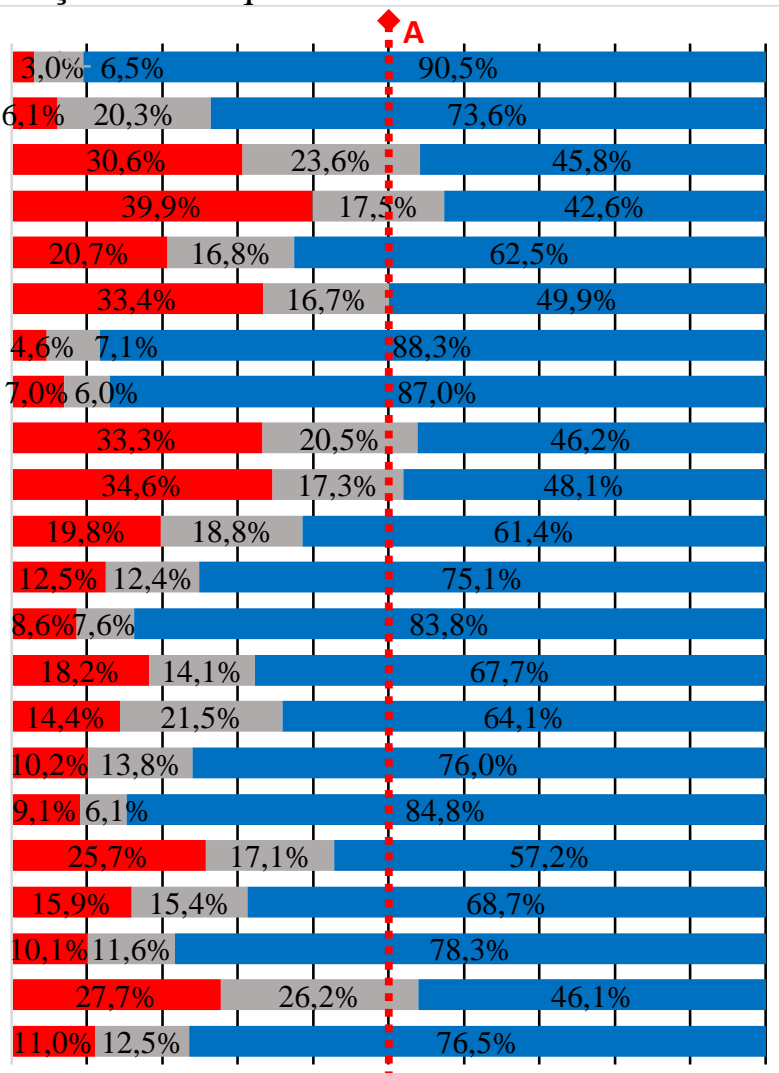

$\begin{array}{llllllllllll}0 \% & 10 \% & 20 \% & 30 \% & 40 \% & 50 \% & 60 \% & 70 \% & 80 \% & 90 \% & 100 \%\end{array}$

$\square$ Insatisfeito $\square$ Neutro $\square$ Satisfeito

Fonte: elaboração própria.

No entanto, os pontos A e B da Figura 2 consideram como corte de avaliação para possíveis melhorias no transporte público do município de Estrela (RS) os atributos com avaliações inferiores a 50\% de satisfação, sendo eles: 1 - Segurança para viajar em pé $(46,1 \%$ de satisfeitos apenas); 13 - Cobertura das paradas de ônibus (48,1\% de satisfeitos); 14 - Bancos para sentar nas paradas (46,2\% de satisfeitos); 17 - Disponibilidade dos horários em locais visíveis nos ônibus (49,9\% de satisfeitos); 19 - Informação do itinerário e horário nas paradas (42,6\% de satisfeitos) e, 20 - Preço das passagens de ônibus (45,8\% de satisfeitos apenas). O atributo preço, nos estudos de Efthymiou e Antoniou (2017), foi um motivo para a redução no uso de transporte coletivo e teve impacto claro sobre a insatisfação dos entrevistados. Portanto, 
esses aspectos de insatisfação elencados representam atributos de melhoria nos serviços de transporte público urbano no município de Estrela por parte do operador de serviços e da prefeitura. Destaca-se que a retenção de clientes e a atração de novos usuários podem ser alcançadas aumentando-se a qualidade nos serviços de transporte coletivo (ABENOZA; CATS; SUSILO, 2017; GRISÉ; EL-GENEIDY, 2017).

Foi realizado também o teste de Spearman, a fim de complementar e identificar o grau de correlação entre as variáveis: Satisfação Global e Nova Utilização do Serviço de Transporte Coletivo. De acordo com Gujarati (2006), por definição, a correlação de uma variável com ela mesma é sempre igual a 1 . O teste revela o grau de relacionamento entre as variáveis estudadas. A Tabela 2 apresenta a correlação de Spearman relacionando as variáveis Satisfação Global e Utilização do Serviço de Transporte Novamente (Nova Viagem).

Tabela 2 - Correlação de Spearman

\begin{tabular}{llrr}
\hline Variáveis & Itens & Satisfação Global & Nova Viagem \\
\hline \multirow{2}{*}{ Satisfação Global } & Correlações de coeficiente & 1,000 &, $418^{* *}$ \\
& Sig. (2 extremidades) &. &, 000 \\
\hline \multirow{2}{*}{ Nova Viagem } & Correlações de coeficiente &, $418^{* *}$ & 1,000 \\
& Sig. (2 extremidades) &, 000 &.
\end{tabular}

Nota (**): A correlação é significativa no nível 0,01 (2 extremidades).

Fonte: elaboração própria.

A Satisfação Global e a Intenção de Nova Viagem se relacionam positivamente (coeficiente de correlação = 0,418), ou seja, quando a Satisfação Global aumenta, a Utilização do Serviço também aumenta (Figura 3), o que pode ser considerado uma correlação significativa moderada e positiva.

Figura 3 - Gráfico da correlação

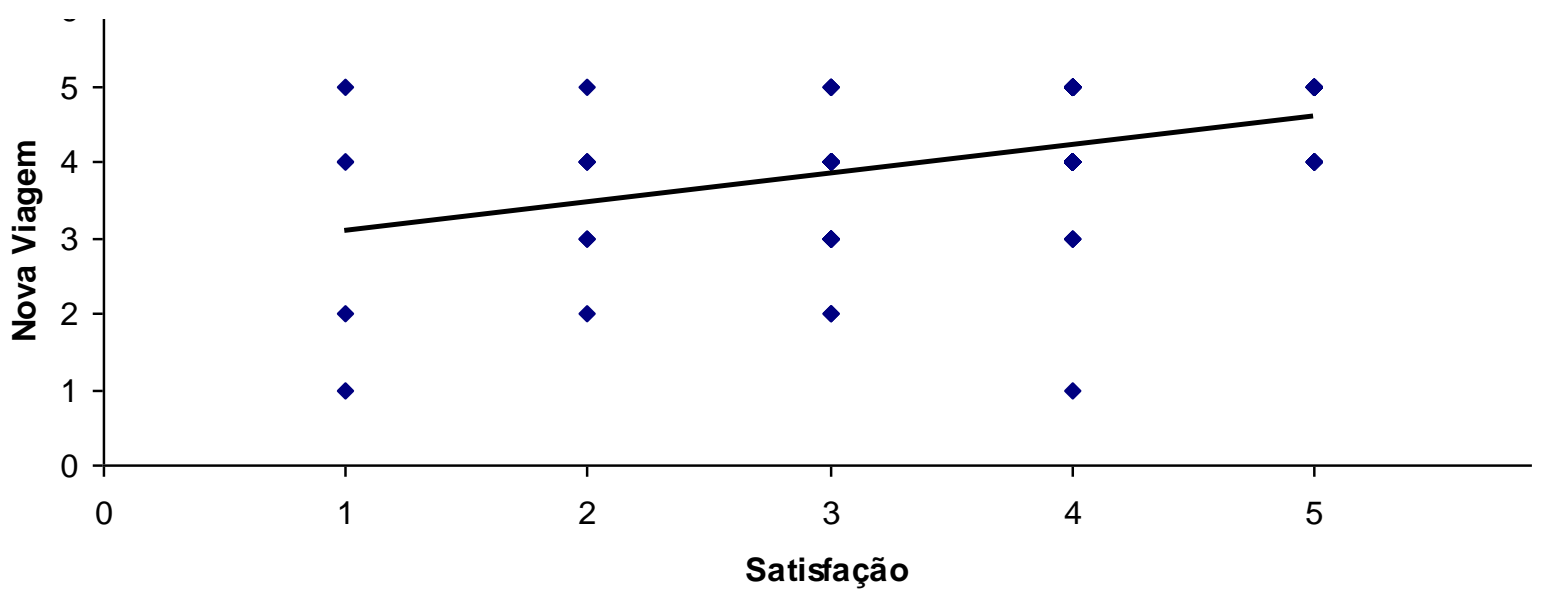

Fonte: elaboração própria. 
Na prática, o teste de correlação demonstra que, havendo uma elevação com os níveis de satisfação dos usuários de transporte público de Estrela, haverá uma tendência de reutilização dos serviços, confirmando a ligação entre qualidade no serviço e aumento da utilização de transporte coletivo (EPSTEIN; GIVONI, 2016). Portanto, a redução nos níveis de insatisfação com os atributos promoverá uma tendência de elevação na satisfação geral e, consequentemente, a reutilização e permanência com os serviços de ônibus urbano no município. Isso representa menos veículos e menos poluição na cidade, bem como maior mobilidade urbana, ou seja, quanto mais satisfeito os usuários estiverem com a qualidade do serviço, maior será a utilização do serviço de transporte (LAI; CHEN, 2011; EFTHYMIOU; ANTONIOU, 2017). As estatísticas também revelaram não haver diferenças significativas entre as variáveis de escolaridade, gênero e estado civil em relação à satisfação global do serviço de transporte coletivo do estudo.

A partir destes resultados, foi possível avançar nas análises para identificar os fatores de maior relevância que impactam na satisfação com a qualidade dos serviços de transporte público no município. Hair et al. (2009) definem fator como a combinação linear das variáveis (estatísticas) originais. Segundo os autores, as técnicas de Análise Fatorial (AF) devem cumprir dois objetivos: identificar a estrutura por meio de resumo de dados ou reduzir os dados.

O teste KMO (Kaiser-Meyer-Olklin), que indica se as variáveis adotadas são capazes de sustentar a utilização da AF de forma satisfatória, resultou em 0,743, confirmando a possibilidade de utilização da AF para explicar a variação dos dados (HAIR et al., 2009). O teste de esfericidade de Bartlett - Bartlett Test of Sphericity (BTS) verifica se a matriz de correlação é uma matriz identidade, indicando que não há correlação entre os dados. No teste deste estudo, obteve-se a rejeição da hipótese nula (as variáveis são correlacionadas), dando-se sequência à análise fatorial. Os fatores foram identificados com o Método dos Componentes Principais (PCA). Com base na análise fatorial exploratória, as variáveis se mostraram satisfatórias, todas com índices superiores ao limite inferior de corte de 0,50 (HAIR et al., 2009). Confirmando a adequação do uso da AF.

Foram obtidos seis fatores com autovalores (eigenvalues), maiores do que 1, os quais explicam mais de $72 \%$ da variância total das 20 variáveis originais. A análise com a solução rotacionada (rotação varimax) mostra que o $1^{\circ}$ fator passou a explicar $14,774 \%$ da variância total, o $2^{\circ}$ fator explica $13,834 \%$, o $3^{\circ}$ fator $13,481 \%$, o $4^{\circ}$ fator $10,283 \%$, o $5^{\circ}$ fator $10,035 \%$ e o $6^{\circ}$ fator 9,802 da variância total (Tabela 3). 
Tabela 3 - Matriz da quantidade de fatores através do método de análise dos fatores principais com solução rotacionada

\begin{tabular}{lrrrrrr}
\multirow{2}{*}{ Fator } & \multicolumn{3}{c}{ Valores próprios iniciais } & \multicolumn{3}{c}{ Somas rotativas de carregamentos ao quadrado } \\
\cline { 2 - 7 } & Total & \% de Variância & \% Cumulativa & Total* & \% de Variância & \% Cumulativa \\
\hline 1 & 4,941 & 29,065 & 29,065 & 2,512 & 14,774 & 14,774 \\
2 & 2,208 & 12,986 & 42,051 & 2,352 & 13,834 & 28,608 \\
3 & 1,523 & 8,960 & 51,011 & 2,292 & 13,481 & 42,089 \\
4 & 1,328 & 7,813 & 58,824 & 1,748 & 10,283 & 52,372 \\
5 & 1,213 & 7,135 & 65,959 & 1,706 & 10,035 & 62,407 \\
6 & 1,063 & 6,250 & 72,209 & 1,666 & 9,802 & 72,209 \\
\hline
\end{tabular}

Nota $(*)$ : O método identifica a existência do número de dimensões, com base na análise de cada valor próprio inicial, que deve ser acima de 1,0 .

Fonte: elaboração própria.

Ferraz e Torres (2004) ressaltam que a qualidade do transporte público urbano pode ser mensurada pelos seus usuários, através de alguns fatores, os quais se reduziram neste estudo, a partir da análise fatorial, em seis (Tabela 4).

Tabela 4 - Matriz de componentes principais dos fatores com solução rotacionada

\begin{tabular}{|c|c|c|c|c|c|c|}
\hline \multirow{2}{*}{ Variáveis/atributos analisadas } & \multicolumn{6}{|c|}{ Componentes principais (Fatores) } \\
\hline & 1 & 2 & 3 & 4 & 5 & 6 \\
\hline 15 - Motorista cordial, simpático e atencioso &, 930 &, 119 &, 132 &, 104 & 088 & 063 \\
\hline 16 - Motorista educado & , 924 &, 114 &, 185 &, 097 & 065 & 037 \\
\hline 06 - Com relação ao número de linhas disponíveis & , 648 &, 137 &, 101 &, 327 & 048 & 277 \\
\hline 19 - Informações do itinerário e horários nas paradas &,- 004 & , 890 &, 023 &, 118 &, 029 &, 019 \\
\hline 17 - Horários estão disponíveis em local visível nos veículos & , 092 &, 861 &, 136 & , 138 &,- 027 &,- 062 \\
\hline 18 - Identificação dos veículos com o itinerário &, 251 &, 810 &, 126 &, 028 &,- 030 &, 053 \\
\hline 04 - Com relação ao espaço dos veículos &, 140 &,- 047 & , 771 &, 174 &, 029 &, 070 \\
\hline 02 - Com relação à segur & 062 &, 063 &, 726 &,- 044 & 274 & 051 \\
\hline 05 - Com relação ao espa &, 045 &, 191 &, 695 &, 124 & 021 & 124 \\
\hline 01 - Com relação ao estado de conservação dos veíc &, 276 &, 145 & , 616 &, 238 &, 010 &, 177 \\
\hline 20 - Com relação ao preço praticado na passagem & 057 &, 207 &,- 020 &, 762 & 073 &,- 075 \\
\hline 08 - Com relação ao núme &, 104 &, 070 &, 292 &, 657 & 089 &, 126 \\
\hline 09 - Com relação ao cumprimento dos horários &, 348 &,- 007 &, 225 &, 664 &, 090 &, 128 \\
\hline 13 - Com relação à cobertura das paradas & 017 &,- 049 &, 082 &, 075 &, 894 &, 103 \\
\hline 14 - Com relação a bancos para sentar nas paradas &, 145 &, 024 &, 158 &, 137 &, 876 &, 082 \\
\hline 12 - Com relação à segurança e iluminação & 034 &,- 025 &, 146 &, 057 & , 046 &, 888 \\
\hline 11 - Com relação à limpeza &, 208 &, 023 &, 153 &, 050 &, 151 &, 824 \\
\hline
\end{tabular}

Nota: Método de extração: Análise de Componentes principais. Método de rotação: Varimax com normalização de Kaiser. Rotação convergida em 6 iterações. Foram agrupadas 17 variáveis com carga fatorial acima de 0,60; as demais foram excluídas.

Fonte: elaboração própria.

O primeiro fator, denominado de Atendimento ao Passageiro, é explicado pelas variáveis: motorista cordial, simpático e atencioso com uma carga fatorial de 0,930; seguido por motorista educado, com 0,924, e número de linhas disponíveis aos passageiros, com 0,648 de carga fatorial. O segundo fator, chamado Informações ao Passageiro, é explicado pelas variáveis: informações do itinerário e horários nas paradas $(0,890)$, horários estão disponíveis em local visível nos veículos $(0,861)$ e identificação dos veículos com o itinerário $(0,810)$. O terceiro fator, denominado Veículo de Transporte, é explicado por: espaço dos veículos $(0,771)$, segurança para quem viaja de pé $(0,726)$, espaço destinado para idosos e PNE $(0,695)$ 
e estado de conservação dos veículos $(0,616)$. O quarto fator, denominado Serviço de Transporte Público, é explicado por preço da passagem (0,762), número de veículos por linha $(0,657)$ e com relação ao cumprimento dos horários $(0,664)$. O quinto fator, denominado Estrutura das Paradas de Ônibus, é explicado por: cobertura $(0,894)$ e bancos para sentar nas paradas $(0,876)$. O sexto e último fator, denominado de Ambiente das Paradas, é explicado por segurança e iluminação $(0,888)$ e por limpeza nas paradas de ônibus $(0,824)$.

Em outro estudo conduzido por Oña et al. (2013), realizado na Espanha, os autores obtiveram como resultado três fatores genéricos ou construtos percebidos na qualidade dos ônibus: Serviço do ônibus (Frequência de viagens, pontualidade, rapidez, proximidade, tarifa e informações), Conforto do veículo (Limpeza, espaço interno, temperatura ambiente e acessibilidade do veículo) e Relacionamento pessoal (Segurança e cortesia do condutor).

Por fim, em uma análise complementar de regressão múltipla considerando como variável dependente a Questão 21, referente a Satisfação Global dos usuários de serviço de transporte e tendo como variáveis independentes os seis fatores identificados, resultou em um coeficiente de determinação ajustado ( $\mathrm{R}^{2}$ ajustado) do modelo de regressão de 0,4 . Ou seja, $40 \%$ das variações na satisfação global com o serviço de transporte coletivo são explicadas pelos seis fatores obtidos com a análise fatorial. Este, juntamente com o Teste ANOVA realizado (valor $p$ de 0,000 ), indica que as variações (da variável dependente - 21 Como você avalia a sua satisfação global [geral] com o serviço?) explicadas pelo modelo não se devem apenas ao acaso. Todos os coeficientes da equação de regressão considerando os seis fatores também foram significativos no modelo. Nos estudos de Abenoza, Cats e Susilo (2017), a satisfação do cliente é definida como a medida em que a prestação de serviços atende às necessidades dos clientes, aqui representadas pelos fatores identificados.

Portanto, os fatores com impacto direto sobre a satisfação dos usuários de transporte público urbano de Estrela representam informações importantes para a prefeitura, que poderá incluí-los na fiscalização dos serviços e nas licitações como fatores primordiais para que o operador atenda com qualidade ao transporte coletivo. Já para as empresas que realizam o transporte público urbano, esses fatores representam informações estratégicas de qualidade dos serviços prestados considerando a satisfação do seu público-alvo, o passageiro. Tyrinopoulos e Antoniou (2008) destacam que avaliar e melhorar a qualidade do serviço deve ser uma prioridade dos operadores de transporte público, seja por tentar reduzir o crescente número de automóveis no tráfego das vias ou por contribuir para a mobilidade urbana sustentável. 
Para aumentar a escolha por transporte público, é fundamental que o cliente esteja satisfeito e perceba que o serviço prestado atingiu ou excedeu suas expectativas. O cliente, quando tem suas necessidades atendidas, possui uma tendência de retorno ao serviço (SHAN et al., 2014).

\section{CONSIDERAÇÕES FINAIS}

O constante crescimento das cidades ocasiona congestionamento e falta de espaço nas vias urbanas. A cada dia, mais veículos circulam por vias públicas, transtorno que pode ser em parte resolvido com a utilização do transporte público de modo a reduzir o tráfico de veículos particulares em vias urbanas, reduzindo o congestionamento e a poluição nas cidades brasileiras. Nos estudos de Fiorio, Florio e Perucca (2013), muitos dos entrevistados relataram satisfação em utilizar o transporte coletivo visando reduzir o número de carros nas vias, na intenção de reduzir os congestionamentos. No entanto, só haverá uma migração de grande escala para o transporte público nas cidades se a população tiver dele uma boa imagem e identificar benefícios superiores aos custos incorridos, o que torna o objetivo inicial deste estudo de importância social e prática, ao identificar os atributos qualitativos e seus fatores que impactam na satisfação com a qualidade dos serviços de transporte público urbano de ônibus.

O objetivo foi plenamente atingido com a realização desta pesquisa. Primeiramente, buscou-se identificar os atributos que integram e influenciam a satisfação dos usuários com a qualidade do transporte coletivo de um município brasileiro (Estrela). A partir de uma entrevista com 25 usuários, obteve-se uma lista de 20 atributos, categorizados em seis dimensões teóricas, corroborando os estudos de Barcelos et al. (2017b), acerca da importância dos atributos no transporte coletivo. Com estes dados qualitativos, foi possível construir o questionário que serviu de instrumento de pesquisa para mensurar a satisfação com os atributos que impactam na qualidade dos serviços de transporte coletivo de Estrela (RS). Utilizou-se uma amostra de 203 usuários de ônibus para avaliar a satisfação com o serviço de transporte público urbano do município. Os resultados foram positivos, com 73,7\% dos usuários satisfeitos com o serviço e 90,4\% afirmando que voltariam a utilizar o transporte público. O teste de correlação de Spearman demonstrou uma correlação positiva e significante entre satisfação e reutilização do transporte público, corroborando outros estudos (EPSTEIN; GIVONI, 2016) e comprovando a importância de ações na melhoria dos serviços que visem à satisfação com a qualidade para continuidade da utilização do transporte coletivo urbano. Para Hernandez, Monzon e De Oña 
(2016), as perspectivas dos usuários de transporte coletivo, são importantes para determinar as melhores medidas políticas no transporte público. Além de fornecer dados para realização de benchmarking com foco na satisfação dos usuários do transporte coletivo por ônibus (BARCELOS et al., 2017a).

Os resultados obtidos com a análise fatorial permitiram identificar seis fatores significativos, que predominam no serviço de transporte público por ônibus e explicam $40 \%$ da satisfação global com o serviço, contribuindo com outros estudos no Brasil (FERRAZ; TORRES, 2004; RODRIGUES, 2006). Eis os fatores identificados: Atendimento ao Passageiro; Informações ao Passageiro; Veículo de Transporte; Serviço de Transporte Público; Estrutura das Paradas de Ônibus e Ambiente das Paradas. Portanto, os atributos qualitativos e seus respectivos fatores identificados por este estudo são contribuições de ordem acadêmica e também podem contribuir para subsidiar a administração pública na elaboração de planejamentos e licitações, além de conter informações relevantes aos prestadores dos serviços de transporte coletivo interessados na qualidade e satisfação dos passageiros. Segundo Jaśkiewicz e Besta (2014), o uso do transporte coletivo exerce importância na qualidade de vida das pessoas, sobretudo em grandes centros urbanos, onde a mobilidade é fundamental para a população. O estudo destaca a importância da satisfação global dos usuários do serviço, bem como as contribuições que partem da identificação dos atributos e de seus fatores para a satisfação dos usuários, sobretudo na influência do comportamento de avaliação da satisfação das pessoas que utilizam o serviço de transporte coletivo, podendo ser considerado como mais uma referência para futuros estudos em trabalhos semelhantes que envolvam a qualidade no transporte coletivo urbano no país, considerando os poucos estudos e ainda incipientes acerca do tema no Brasil.

Destacam-se ainda as contribuições práticas para a administração do serviço de transporte coletivo local e da prefeitura de Estrela (RS). Os seis fatores que resultaram do estudo caracterizam fatores críticos de sucesso para os usuários do transporte coletivo no município gaúcho, os quais devem ser monitorados pelo poder público local e pelas empresas que realizam o respectivo serviço de transporte, visando à satisfação dos usuários e à elevação do número de usuários do referido transporte de modo a reduzir o congestionamento na cidade. Oña et al. (2013) destacam que cabe aos operadores de ônibus melhorar constantemente o desempenho da qualidade dos serviços de transporte coletivo, pois dessa forma se eleva consideravelmente a satisfação geral dos passageiros. 
Sugere-se como ações de melhoria que, nos pontos de informações, sejam afixados cartazes ou placas indicando os horários de circulação e o trajeto percorrido em cada linha, tanto na parte interna dos veículos, como nas paradas de ônibus, assim como a criação de um website ou aplicativo móvel específico informando tais horários. Os veículos também devem estar identificados por suas respectivas linhas e horários. O preço praticado, outro ponto de insatisfação na análise da pesquisa, sugere a importância de que o poder público municipal examine o real custo de cada linha e a possibilidade de alterar trajetos. Também é necessário investir recursos públicos, de forma gradativa, na melhoria da estrutura física das paradas de ônibus de Estrela, visando à cobertura e à disponibilização de bancos para que os passageiros possam, de forma mais confortável, aguardar os veículos em seus horários de circulação. Por fim, este estudo serve para fornecer ferramentas e informações aplicáveis para tornar o ciclo de melhoria um processo contínuo no transporte coletivo urbano das cidades, servindo inclusive como benchmarking e respaldado por pesquisa pública visando à qualidade de vida e mobilidade da população.

Uma das limitações do estudo é a não possibilidade de generalizar os resultados, tendo em vista que a pesquisa se restringiu a uma única cidade - Estrela (RS) - e a um único meio de transporte coletivo: o ônibus. Além disso, o estudo teve uma amostra não probabilística, não permitindo conclusões definitivas. Os atributos e fatores identificados pela pesquisa são exclusivos para atender a este estudo, portanto se reaplicado por outros pesquisadores, caberá uma comparação tendo como referência os resultados divulgados, os quais contribuem para ampliar o conhecimento do tema.

Para pesquisas futuras, recomenda-se reaplicar a metodologia adotada, com amostras de usuários de serviços de transporte coletivo de outras cidades do Brasil, assim como usuários de serviços de outros meios de transporte, como: táxi, trem, metrô... Também existe a possibilidade de confrontar os atributos e os fatores identificados por este estudo com outros trabalhos semelhantes envolvendo o transporte coletivo em regiões diferentes do país. Estudos relativos à influência sociocultural sobre os atributos e fatores de satisfação regional com o transporte coletivo também é um tema a ser explorado. Por fim, é possível ainda um estudo dos fatores motivacionais envolvendo classe social para adoção do transporte coletivo nas cidades brasileiras. Portanto, a partir deste artigo, outras pesquisas poderão ser realizadas objetivando a ampliação e a compreensão da satisfação dos usuários com a qualidade dos serviços de transporte público urbano no país, a exemplo de estudos realizados em outras cidades no mundo e ainda incipientes no Brasil. 


\section{REFERÊNCIAS}

ABENOZA, R. F.; CATS, O.; SUSILO, Y. O. Travel satisfaction with public transport: Determinants, user classes, regional disparities and their evolution. Transportation Research Part A: Policy and Practice, v. 95, p. 64-84, 2017.

ANDREASSEN, T. W.; LINDESTAD, B. Customer loyalty and complex services: The impact of corporate image on quality, customer satisfaction and loyalty for customers with varying degrees of service expertise. International Journal of Service Industry Management, v. 9, n. 1, p. 7-23, 1998.

ARAÚJO, L. A. D.; MAIA, M. A cidade, o dever constitucional de inclusão social e a acessibilidade. Revista de Direito da Cidade, v. 8, n. 1, p. 225-244, 2016.

BARCELOS, M. M. et al. Benchmarking com foco na satisfação dos usuários do transporte coletivo por ônibus. Transportes, v. 25, n. 3, p. 115-125, 2017a.

Inferindo a importância dos atributos do transporte coletivo a partir da satisfação dos usuários. Transportes, v. 25, n. 5, p. 36-48, 2017 b.

BERRY, L. Revisiting big ideas in services marketing 30 years later. Journal of Services Marketing, v. 30, n. 1, p. 3-6, 2016.

BRASIL. Constituição da República Federativa do Brasil. 1988. Disponível em: <http://www.planalto.gov.br/ccivil_03/constituicao/constituicao.htm>. Acesso em: 22 mai. 2016.

Lei $\mathrm{n}^{\mathrm{o}}$ 10.257, de 10 de julho de 2001. Disponível em:

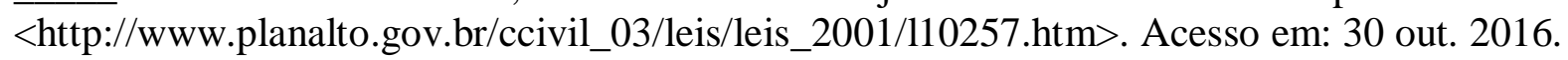

Lei $\mathrm{n}^{\mathrm{o}}$ 12.587, de 3 de janeiro de 2012. Disponível em: <http://www.planalto.gov.br/ccivil_03/_ato2011-2014/2012/lei/112587.htm>. Acesso em: 30 jul. 2016.

Lei Complementar $\mathrm{n}^{\circ}$ 90, de 15 de setembro de 2015. Disponível em: <http://www.planalto.gov.br/ccivil_03/constituicao/emendas/emc/emc90.htm>. Acesso em: 22 mai. 2016. 
BRONS, M.; GIVONI, M.; RIETVELD, P. Access to railway stations and its potential in increasing rail use. Transportation Research Part A: Policy and Practice, v. 43, n. 2, p. 136149, 2009.

CHARBATZADEH, F. et al. Determinants of satisfaction with campus transportation services. Implications for service quality. Journal of Transport and Supply Chain Management, v. 10, n. 1, p. 1-14, 2016.

COCCO, R. G.; MIRALLES-GUASCH, C. As manifestações pelo transporte público no Brasil: Uma leitura distinta a partir do caso da grande Florianópolis, Estado de Santa Catarina. Scripta Nova - Revista Electrónica de Geografía y Ciencias Sociales, v. 20, p. 527-551, 2016.

COOPER, D. R.; SCHINDLER, P. S. Métodos de pesquisa em administração. 12. Ed. Porto Alegre: Bookman, 2016.

DE OÑA, J.; DE OÑA, R.; LÓPEZ, G. Transit service quality analysis using cluster analysis and decision trees: A step forward to personalized marketing in public transportation. Transportation, v. 43, n. 5, p. 725-747, 2016.

DÍAZ, L. D.; BERNABÉ, N. Q. Análisis del movimiento de pasajeros en la ruta 447 MorónCiego de Ávila. Journal of Transport Literature, v. 9, n. 4, p. 20-24, 2015.

EFTHYMIOU, D.; ANTONIOU, C. Understanding the effects of economic crisis on public transport users' satisfaction and demand. Transport Policy, v. 53, n. C, p. 89-97, 2017.

ENDERS, T. W.; MENDES, N. M. M.; HESKETH, J. L. A pesquisa de percepções individuais aplicada às áreas de administração e planejamento: Conceitos, teoria e metodologia. Revista de Administração, v. 18, n. 1, p. 23-31, 1983.

EPSTEIN, B.; GIVONI, M. Analyzing the gap between the QOS demanded by PT users and QOS supplied by service operators. Transportation Research Part A: Policy and Practice, v. 94, n. C, p. 622-637, 2016.

FERRAZ, A. C. P.; TORRES, I. G. E. Transporte público urbano. São Paulo: Rima, 2004.

FILIPPINI, M.; KOLLER, M.; MASIERO, G. Competitive tendering versus performancebased negotiation in Swiss public transport. Policy and Practice, v. 82, n. 1, p. 158-168, 2015. 
FIORIO, C. V.; FLORIO, M.; PERUCCA, G. User satisfaction and the organization of local public transport: Evidence from European cities. Transport Policy, n. 29, n. C, p. 209-218, 2013.

FLANAGAN, J. C. The critical incident technique. Psychological Bulletin, v. 51, n. 4, p. $327-$ 358, 1954.

GIVONI, M.; RIETVELD, P. The access journey to the railway station and its role in passengers' satisfaction with rail travel. Transport Policy, v. 14, n. 5, p. 357-365, 2007.

GRISÉ, E.; EL-GENEIDY, A. Evaluating the relationship between socially (dis) advantaged neighbourhoods and customer satisfaction of bus service in London, UK. Journal of Transport Geography, v. 58, n. 1, p. 166-175, 2017.

GUIRAO, B.; GARCÍA-PASTOR, A.; LÓPEZ-LAMBAS, M. E. The importance of service quality attributes in public transportation: Narrowing the gap between scientific research and practitioners' needs. Transport Policy, v. 49, p. 68-77, 2016.

GUJARATI, D. Econometria Básica. 4. Ed. Rio de Janeiro: Campus, 2006.

HAIR, J. F. et al. Análise multivariada de dados. 6. Ed. Porto Alegre: Bookman, 2009.

HENSHER, D. A.; HO, C.; MULLEY, C. Identifying preferences for public transport investments under a constrained budget. Transportation Research Part A: Policy and Practice, v. 72, n. C, p. 27-46, 2015.

HENSHER, D. A.; STOPHER, P.; BULLOCK, P. Service quality - developing a service quality index in the provision of commercial bus contracts. Transportation Research Part A: Policy and Practice, v. 37, n. 6, p. 499-517, 2003.

HERNANDEZ, S.; MONZON, A.; DE OÑA, R. Urban transport interchanges: A methodology for evaluating perceived quality. Transportation Research Part A: Policy and Practice, v. 84, n. C, p. 31-43, 2016.

IPEA. Instituto de Pesquisa Econômica Aplicada. 2017. Disponível em: <http://www.ipea.gov.br/portal>. Acesso em: 25 mar. 2017.

ISLAM, M. R. et al. Bus service quality prediction and attribute ranking: A neural network approach. Public Transport, v. 8, n. 2, p. 295-313, 2016. 
JAŚKIEWICZ, M.; BESTA, T. Heart and mind in public transport: Analysis of motives, satisfaction and psychological correlates of public transportation usage in the Gdańsk-Sopot Gdynia Tricity Agglomeration in Poland. Transportation Research Part F: Traffic Psychology and Behaviour, v. 26, n. A, p. 92-101, 2014.

LAI, W. T.; CHEN, C. F. Behavioral intentions of public transit passengers - The roles of service quality, perceived value, satisfaction and involvement. Transport Policy, v. 18, n. 2, p. 318-325, 2011.

LIMA, K. R.; MOURA, L. R. C.; SOUKI, G. Q. A avaliação da qualidade de um sistema de metrô. Revista Inteligência Competitiva, v. 5, n. 3, p. 14-34, 2015.

LUBECK, R. M. et al. Qualidade no transporte coletivo urbano. FACEF Pesquisa, v. 14, n. 3, p. 264-277, 2011.

MALHOTRA, N. Pesquisa de Marketing: Uma orientação aplicada. 6. Ed. Porto Alegre: Bookman, 2011.

MICHAELIS. Dicionário da língua portuguesa. 2017. Disponível em: <http://michaelis.uol.com.br>. Acesso em: 01 fev. 2017.

MOUWEN, A. Drivers of customer satisfaction with public transport services. Transportation Research Part A: Policy and Practice, v. 78, n. C, p. 1-20, 2015.

MURÇA, M. C. R.; MÜLLER, C. Transporte coletivo urbano: uma análise de demanda para a cidade de Salvador. Journal of Transport Literature, v. 8, n. 1, p. 265-284, 2014.

OÑA, J. et al. Perceived service quality in bus transit service: A structural equation approach. Transport Policy, v. 29, n. set., p. 219-226, 2013.

PAIVA JUNIOR, H. Segmentação e modelagem comportamental de usuários dos serviços de transporte urbano brasileiros. 2006. Tese (Doutorado em Engenharia) - Escola Politécnica da Universidade de São Paulo, São Paulo, 2006.

RAHMAN, F. et al. Perceived service quality of paratransit in developing countries: A structural equation approach. Transportation Research Part A: Policy and Practice, v. 93, n. C, p. 23-38, 2016.

RODRIGUES, M. O. Avaliação do transporte coletivo da cidade de São Carlos. 2006. 
Dissertação (Mestrado em Engenharia). Universidade de São Paulo, São Paulo, 2006.

SHAABAN, K.; KIM, I. The influence of bus service satisfaction on university students' mode choice. Journal of Advanced Transportation, v. 50, n. 6, p. 935-948, 2016.

SHAN, S.; LI, C; YAO, W; SHI, J; REN, J. An empirical study on critical factors affecting employee satisfaction. Systems Research and Behavioral Science, v. 31, n. 3, p. 447-460, 2014.

THOMPSON, K.; SCHOFIELD, P. An investigation of the relationship between public transport performance and destination satisfaction. Journal of Transport Geography, v. 15, n. 2, p. 136-144, 2007.

TYRINOPOULOS, Y; ANTONIOU, C. Public transit user satisfaction: Variability and policy implications. Transport Policy, v. 15, n. 4, p. 260-272, 2008. 